Network Working Group

Request for Comments: 2468

Category: Informational
V. Cerf

MCI

October 1998

\title{
I REMEMBER IANA
}

October 17,1998

\section{Status of this Memo}

This memo provides information for the Internet community. It does not specify an Internet standard of any kind. Distribution of this memo is unlimited.

Copyright Notice

Copyright (C) The Internet Society (1998). All Rights Reserved.

Remembrance

A long time ago, in a network, far far away, a great adventure took place!

Out of the chaos of new ideas for communication, the experiments, the tentative designs, and crucible of testing, there emerged a cornucopia of networks. Beginning with the ARPANET, an endless stream of networks evolved, and ultimately were interlinked to become the Internet. Someone had to keep track of all the protocols, the identifiers, networks and addresses and ultimately the names of all the things in the networked universe. And someone had to keep track of all the information that erupted with volcanic force from the intensity of the debates and discussions and endless invention that has continued unabated for 30 years. That someone was Jonathan $B$. Postel, our Internet Assigned Numbers Authority, friend, engineer, confidant, leader, icon, and now, first of the giants to depart from our midst.

Jon, our beloved IANA, is gone. Even as I write these words I cannot quite grasp this stark fact. We had almost lost him once before in 1991. Surely we knew he was at risk as are we all. But he had been our rock, the foundation on which our every web search and email was built, always there to mediate the random dispute, to remind us when our documentation did not do justice to its subject, to make difficult decisions with apparent ease, and to consult when careful consideration was needed. We will survive our loss and we will remember. He has left a monumental legacy for all Internauts to 
contemplate. Steadfast service for decades, moving when others seemed paralyzed, always finding the right course in a complex minefield of technical and sometimes political obstacles.

Jon and I went to the same high school, Van Nuys High, in the San Fernando Valley north of Los Angeles. But we were in different classes and I really didn't know him then. Our real meeting came at UCLA when we became a part of a group of graduate students working for Professor Leonard Kleinrock on the ARPANET project. Steve Crocker was another of the Van Nuys crowd who was part of the team and led the development of the first host-host protocols for the ARPANET. When Steve invented the idea of the Request for Comments series, Jon became the instant editor. When we needed to keep track of all the hosts and protocol identifiers, Jon volunteered to be the Numbers Czar and later the IANA once the Internet was in place.

Jon was a founding member of the Internet Architecture Board and served continuously from its founding to the present. He was the FIRST individual member of the Internet Society I know, because he and Steve Wolff raced to see who could fill out the application forms and make payment first and Jon won. He served as a trustee of the Internet Society. He was the custodian of the. Us domain, a founder of the Los Nettos Internet service, and, by the way, managed the networking research division of USC Information Sciences Institute.

Jon loved the outdoors. I know he used to enjoy backpacking in the high Sierras around Yosemite. Bearded and sandaled, Jon was our resident hippie-patriarch at UCLA. He was a private person but fully capable of engaging photon torpedoes and going to battle stations in a good engineering argument. And he could be stubborn beyond all expectation. He could have outwaited the Sphinx in a staring contest, I think.

Jon inspired loyalty and steadfast devotion among his friends and his colleagues. For me, he personified the words "selfless service". For nearly 30 years, Jon has served us all, taken little in return, indeed sometimes receiving abuse when he should have received our deepest appreciation. It was particularly gratifying at the last Internet Society meeting in Geneva to see Jon receive the Silver Medal of the International Telecommunications Union. It is an award generally reserved for Heads of State, but I can think of no one more deserving of global recognition for his contributions.

While it seems almost impossible to avoid feeling an enormous sense of loss, as if a yawning gap in our networked universe had opened up and swallowed our friend, I must tell you that I am comforted as I contemplate what Jon has wrought. He leaves a legacy of edited documents that tell our collective Internet story, including not only 
the technical but also the poetic and whimsical as well. He completed the incorporation of a successor to his service as IANA and leaves a lasting legacy of service to the community in that role. His memory is rich and vibrant and will not fade from our collective consciousness. "What would Jon have done?", we will think, as we wrestle in the days ahead with the problems Jon kept so well tamed for so many years.

There will almost surely be many memorials to Jon's monumental service to the Internet community. As current chairman of the Internet Society, I pledge to establish an award in Jon's name to recognize long-standing service to the community, the Jonathan $B$. Postel Service Award, which will be awarded to Jon posthumously as its first recipient.

If Jon were here, I am sure he would urge us not to mourn his passing but to celebrate his life and his contributions. He would remind us that there is still much work to be done and that we now have the responsibility and the opportunity to do our part. I doubt that anyone could possibly duplicate his record, but it stands as a measure of one man's astonishing contribution to a community he knew and loved.

Security Considerations

Security issues are not relevant to this Remembrance.

Author's Address

Vinton G. Cerf

MCI

EMail: vcerf@mci.net 
Full Copyright statement

Copyright (C) The Internet Society (1998). All Rights Reserved.

This document and translations of it may be copied and furnished to others, and derivative works that comment on or otherwise explain it or assist in its implementation may be prepared, copied, published and distributed, in whole or in part, without restriction of any kind, provided that the above copyright notice and this paragraph are included on all such copies and derivative works. However, this document itself may not be modified in any way, such as by removing the copyright notice or references to the Internet society or other Internet organizations, except as needed for the purpose of developing Internet standards in which case the procedures for copyrights defined in the Internet Standards process must be followed, or as required to translate it into languages other than English.

The limited permissions granted above are perpetual and will not be revoked by the Internet society or its successors or assigns.

This document and the information contained herein is provided on an "AS IS" basis and THE INTERNET SOCIETY AND THE INTERNET ENGINEERING TASK FORCE DISCLAIMS ALL WARRANTIES, EXPRESS OR IMPLIED, INCLUDING BUT NOT LIMITED TO ANY WARRANTY THAT THE USE OF THE INFORMATION HEREIN WILL NOT INFRINGE ANY RIGHTS OR ANY IMPLIED WARRANTIES OF MERCHANTABILITY OR FITNESS FOR A PARTICULAR PURPOSE. 